\title{
Partial Discharge Analysis and Simulation Using the Consecutive Pulses Correlation Method
}

\author{
Ondřej Kozák * and Josef Pihera (D)
}

Citation: Kozák, O.; Pihera, J. Partial Discharge Analysis and Simulation Using the Consecutive Pulses Correlation Method. Energies 2021, 14, 2567. https://doi.org/10.3390/ en14092567

Academic Editor: Wei Yao

Received: 18 March 2021

Accepted: 27 April 2021

Published: 29 April 2021

Publisher's Note: MDPI stays neutral with regard to jurisdictional claims in published maps and institutional affiliations.

Copyright: (c) 2021 by the authors. Licensee MDPI, Basel, Switzerland. This article is an open access article distributed under the terms and conditions of the Creative Commons Attribution (CC BY) license (https:// creativecommons.org/licenses/by/ $4.0 /)$.
Department of Materials and Technology, Faculty of Electrical Engineering, University of West Bohemia in Pilsen, 30100 Pilsen, Czech Republic; pihera@ket.zcu.cz

* Correspondence: kozinacze@gmail.com

\begin{abstract}
The behaviour of partial discharge as consequences of an alternating current (AC) is already well defined. AC partial discharges have completely different behaviour, background physics and parameters than partial discharges (PD) under direct current (DC) stress. This paper focuses on the most used and promising evaluation method of the PD DC stress-pulse sequence analysis (PSA). The first step is understanding and verifying the mechanisms and principles of this method. It is provided by well-known fundamentals of AC PD and by comparison with the other diagnostic and fault-locating methods such as phase-resolved partial discharge (PRPD) and pulse diagrams. The paper shows the PSA simulations and PD analyses performed at AC and partly at DC test conditions on typical PD test arrangements such as corona, surface and internal discharges. It is shown that the simulations performed, compared and validated with data obtained from measurements on different PD arrangements are a good match. This fact opens the way for the PD source recognition in DC, especially the time-resolved pulse sequence analysis described in detail in the paper.
\end{abstract}

Keywords: partial discharges; pulse sequence analysis; direct current; simulation

\section{Introduction}

Partial discharge (PD) detection and evaluation is an important tool for electrical insulation systems diagnosis and quality measures. PD behaviour under direct current (DC) voltage stress has to be researched and described because of the increasing implementation of DC voltage into electrical distribution and transmission systems. The greatest need for understanding PD DC lies in the insulation systems used in DC voltage distribution systems. The physical background of the DC PD phenomena needs to be investigated.

Alternating current (AC) PD measurements have well described diagnostic tools which cannot be applied for DC voltage. For this reason, evaluation processes, procedures and methods should be developed for DC conditions. Several studies [1-6] dealt with the PD issues in general. Some of the recent studies [2,7-10] were focused on the PD under DC from a specific point of view-pulse sequence analysis (PSA). The analysis seems to be a method to distinguish the PD type at DC voltage instead of the phase-resolved characteristics used at AC voltage.

The introduced diagnostic method of PSA [9] applied even at DC conditions has been investigated for several years. However, the key parameter of the PD signal that determines the information about the certain type of PD is still missing. Since there is no phase at DC, it is necessary to find other methods and parameters. The presented study shows PSA possibilities for several typical PD arrangements such as corona, surface, and internal discharges. Subsequently, it compares the test results with the PD activity and PSA simulations.

Firstly, the PD at AC voltage is investigated from the standardised and PSA point of view to understand the behaviour of PSA plots. For a better understanding, the mathematical simulations using the Octave programming language is used to explain the PSA 
clusters and their physical background. This comparison was used for the evaluation of PSA method credibility.

Once the PSA clusters are explained for already known typical PD failures at AC and the mechanism of PSA clusters is simulated and experimentally verified, the knowledge could be applied to the DC PD detection and recognition of the PD type.

The Q-Q PSA (dependence of charge values of consecutive pulses) plots were simulated in [7] as the first attempt due to the simplicity of the method. Measurements were compared with the Q-Q PSA simulation to understand the principles of the PSA plot creation. The outcome of this research showed the Q-Q PSA as highly sensitive to even a weak noise with a low repetition rate. This proves the Q-Q PSA as highly uncertain and very difficult to use in a non-laboratory environment. Therefore, the Q-t PSA (dependence of charge and time values of consecutive pulses) was chosen for further investigation.

This paper explains AC and DC voltage measurement conditions and describes different approaches for AC and DC measurements. The next section deals with the experimental setup description and experiment procedure. A PSA and its creation are introduced in Section 2.2. The section three is dedicated to PSA simulation and its comparison with measured AC data. A direct current negative (DCN) corona was measured. Data and further analysis are shown in Section 3.4.

Although PD under DC voltage has the same physical effects as PD under AC voltage, methods or procedures for DC PD evaluation compared to the AC standard EIC 60270 (i.e., phase-resolved partial discharges (PRPD) analysis) are missing. Attempts to create a table of characteristic marks with the effectivity of PRPD were not successful—not even using other statistical variables [11-14].

PRPD analysis is the most common graphic method to represent AC partial discharges. However, PRPD is not suitable for direct current due to the absence of the voltage phase. Despite the graphical representation of the PD, values as apparent charge, charge count and time of the discharge occurrence are still the most important criteria of the PD measurement [15-17].

PSA, originally developed for AC voltage, seems to be a convenient option for graphic DC PD evaluation.

Nevertheless, it must be taken into account that during the measurement and evaluation procedure, the PD measuring system cannot synchronise with the test voltage under DC conditions. This phenomenon causes the incapability of phase-resolved PD patterns evaluation for the direct current tests.

\section{Experiment}

2.1. Experiment Description and Data Acquisition

2.1.1. Setup Description

A standardised PD test circuit consisting of a high voltage source $(\leq 200 \mathrm{kV}$ AC, $\leq 135 \mathrm{kV} \mathrm{DC})$, a coupling capacitor $(\mathrm{C}=1000 \mathrm{pF} \pm 10 \%)$, a measuring impedance (LDM$5 / \mathrm{U}, \mathrm{Z}=50 \Omega$ ) and the partial discharge analyser Doble Lemke PD SMART was used for the PD measurement (see Figure 1). The measurement sensitivity of $\leq 3 \mathrm{pC}$ was reached under the given conditions. The standardised calibration procedure was done using the charge calibrator (LDC-5/S-3) of the system before each measurement. The test voltage was applied for $1 \mathrm{~min}$ for each test. Measurement was performed in the EIC 60270 standard with a dead time of $5 \mu \mathrm{s}$. The threshold value was set individually for each measurement. For the corona measurement (see Figure 2), a needle-plane arrangement in the air was used. The gap distance between the two electrodes was $10 \mathrm{~mm}$ at a tip radius (needle) of $\sim 30 \mu \mathrm{m}$. The surface PD measurement was performed on an arrangement using two parallel round electrodes and Relanex (mica-glass insulating materials using as main wall insulation of rotating machines, thickness $1 \mathrm{~mm}, \varepsilon \mathbf{r} \sim 2.7$ ) insulation between them (see Figure 2). The arrangement for internal PD measurement consists of two round electrodes with PMMA (thickness $2 \mathrm{~mm}, \varepsilon r \sim 3$ ) sandwich insulation with an air cavity (thickness $0.5 \mathrm{~mm}, 1 \mathrm{~mm}$ diameter) immersed in an oil tank with transformer mineral oil (see Figure 2). 


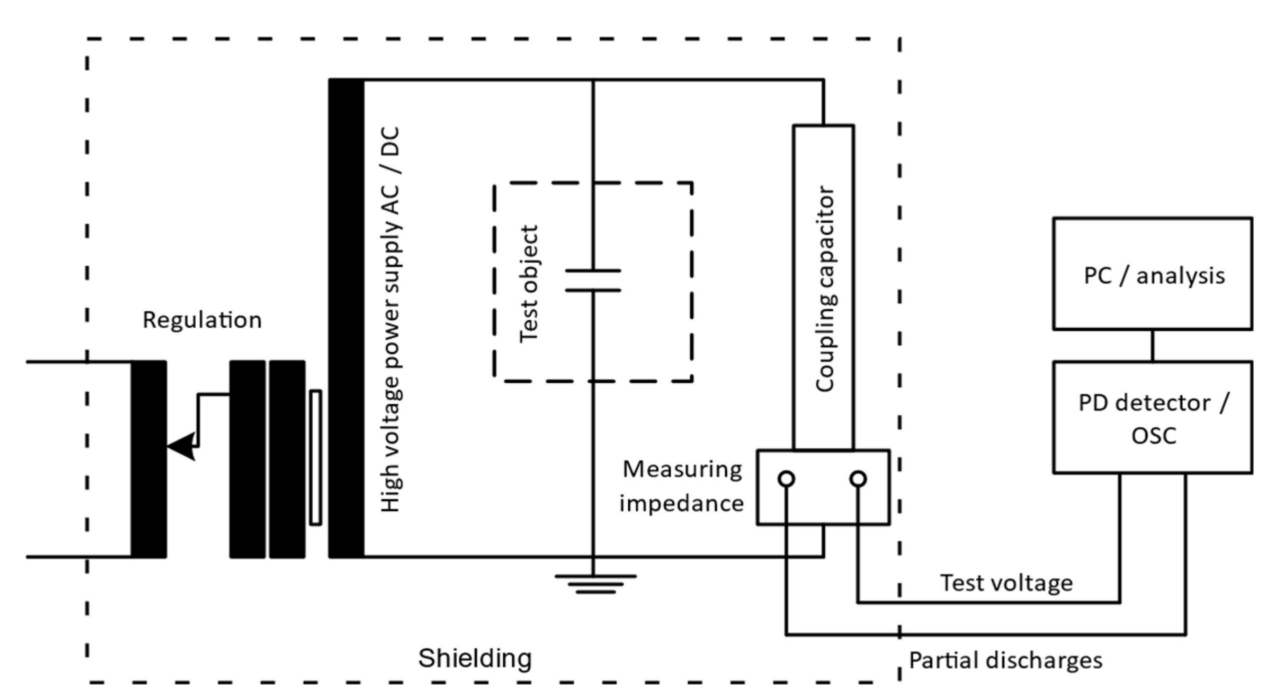

Figure 1. Partial discharge (PD) test circuit.

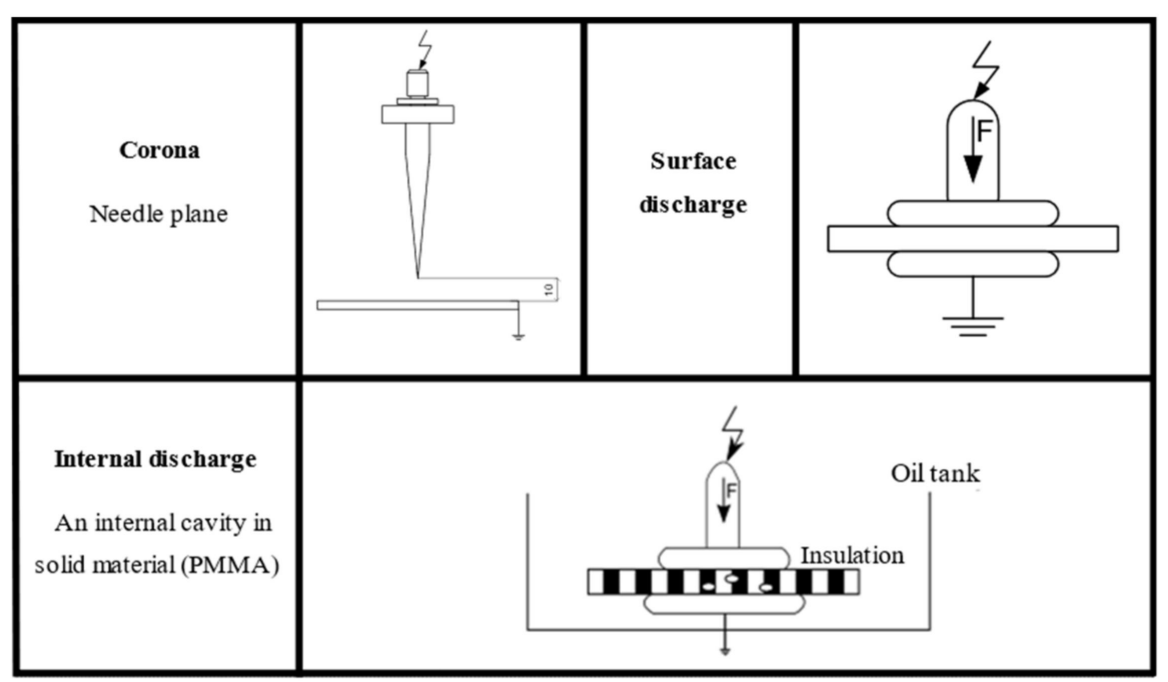

Figure 2. PD test arrangements for corona (top left), surface discharges (top right) and internal discharges (bottom).

\subsubsection{Procedure}

The method of PSA was applied in addition to the standardised measurement according to IEC $60270[18,19]$. The PSA fundamentals are based on the evaluation of consecutive PD pulses. The number of consecutive PD pulses related to the time of occurrence was measured. The time of occurrence of AC PD pulses is correlated to the instantaneous test voltage (Ui) value, at which the PD pulse (Qi) occurs. Therefore, most of the typical results were recorded as $\Delta \mathrm{Qi}-\Delta \mathrm{Ui}$ plots [20]. The physical mechanism within the insulation, e.g., the local electrical field changes by PD pulses, allows deeper investigation, such as evaluation of consecutive discharges. Contrary to the standardised measured parameters as apparent charge $Q$, charge count $n$ etc. [3], the PSA method describes internal field variation. The internal field variation arises between consecutive discharges due to their electric field, which incites the inception of the following pulse.

\subsection{Pulse Sequence Analysis}

R. Patch and M. Hoof introduced PSA in 1993 [20]. Patch and Hoof concluded that the PSA might be a promising method for examination of degradation in insulating materials caused by PD. The PSA was created for the intention of degradation processes under 
AC voltage stress recognition. Nowadays, PRPD analysis is the most used AC partial discharge activity evaluation method. This method uses the phase of the pulse occurrence and apparent charge of the pulse for PD source recognition. Because of the absence of the phase at DC voltage, PRPD analysis is ineligible for this purpose. Many researchers chose the PSA as an elementary approach for a possible fault recognition procedure at DC voltage. Nevertheless, any PSA fundamentals or structure explanation are not interpreted. This paper deals with basic "Q-t PSA" diagrams which are not so frequently published as "Q-Q PSA" diagrams as the outcome of the experimental measurements and PSA plots. "Q-t PSA" provides more information about PD activity [10,11,16,19,20].

PSA is made of at least 3 consecutive pulses (see Figure 3). The most frequently acquired values are apparent charge $Q$, time $t$ (or period and phase) and voltage $U$ of pulse occurrence for AC measurement. In the case of DC voltage stress, the PSA can be used despite a missing phase. Measurement of DC voltage magnitudes is redundant for their constant level. Differences between consecutive pulses shown in Equations (1)-(3) are used for purposes of the PSA $[7,21]$.

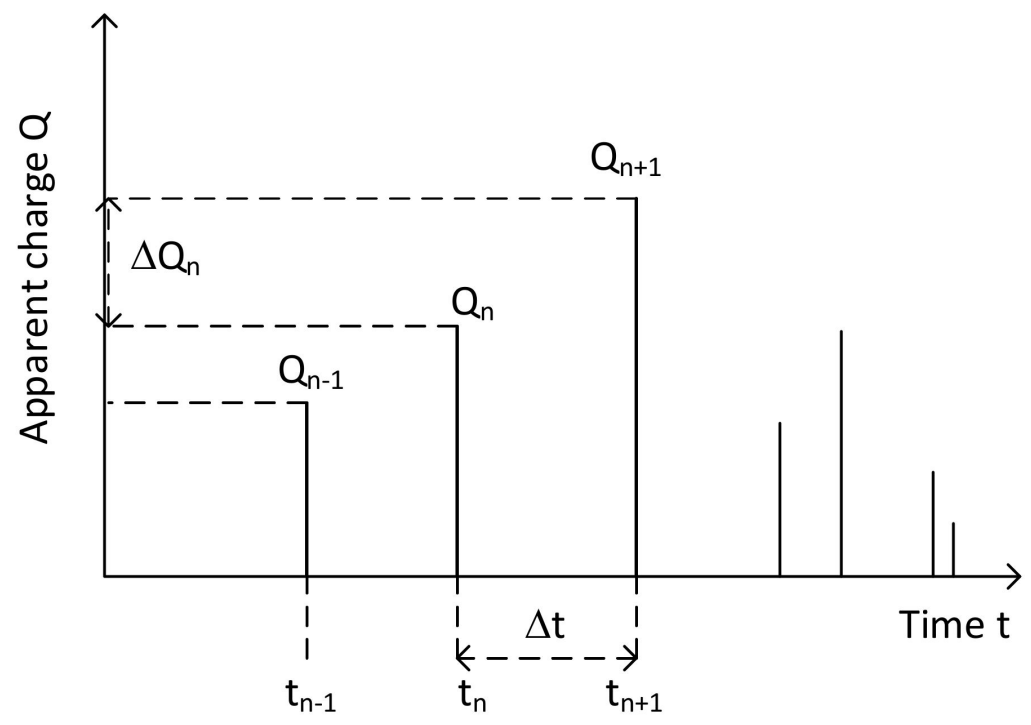

Figure 3. Pulse diagram with used magnitudes for pulse sequence analysis (PSA).

The following basic equations are used to demonstrate the relevant dependencies [7]:

$$
\begin{aligned}
\Delta U_{\mathrm{n}} & =\mathrm{U}_{(\mathrm{n}+1)}-\mathrm{U}_{\mathrm{n}} \\
\Delta \varphi_{\mathrm{n}} & =\varphi_{(\mathrm{n}+1)}-\varphi_{\mathrm{n}} \\
\Delta \mathrm{Q}_{\mathrm{n}} & =\mathrm{Q}_{(\mathrm{n}+1)}-\mathrm{Q}_{\mathrm{n}}
\end{aligned}
$$

There are different approaches for the PSA-the dependence of charge values of consecutive pulses (Q-Q PSA), the dependence of time values of consecutive pulses ( $t-t$ PSA) and the dependence of charge and time values of consecutive pulses (Q-t PSA) shown in Equations (4)-(6) [7]:

$$
\begin{gathered}
\text { Q-Q PSA: } \Delta \mathrm{Q}_{\mathrm{n}}=\mathrm{f}\left(\Delta \mathrm{Q}_{(\mathrm{n}-1)}\right) \\
\text { t-t PSA: } \Delta \mathrm{t}_{\mathrm{n}}=\mathrm{f}\left(\Delta \mathrm{t}_{(\mathrm{n}-1)}\right) \\
\text { Q-t PSA: } \Delta \mathrm{Q}_{\mathrm{n}}=\mathrm{f}\left(\Delta \mathrm{t}_{\mathrm{n}}\right)
\end{gathered}
$$




\section{Results and Discussion}

The Q-t PSA algorithm was programmed in software Octave (high-level programming language, compatible with MATLAB); see diagram in Figure 4. It simulates a sequence of eight PD pulses which is repeated as many times as needed to provide desired points density to form obvious PSA patterns. Eight pulses were chosen as a compromise to achieve reasonable diversity and maintain the algorithm's simplicity. Simulation allows adjusting discharge values of eight separate PD pulses and time steps in between. The number of repetitions can be adjusted manually to obtain the best result. Simulations have been performed to imitate a Q-t PSA from data obtained during real PD measurement.

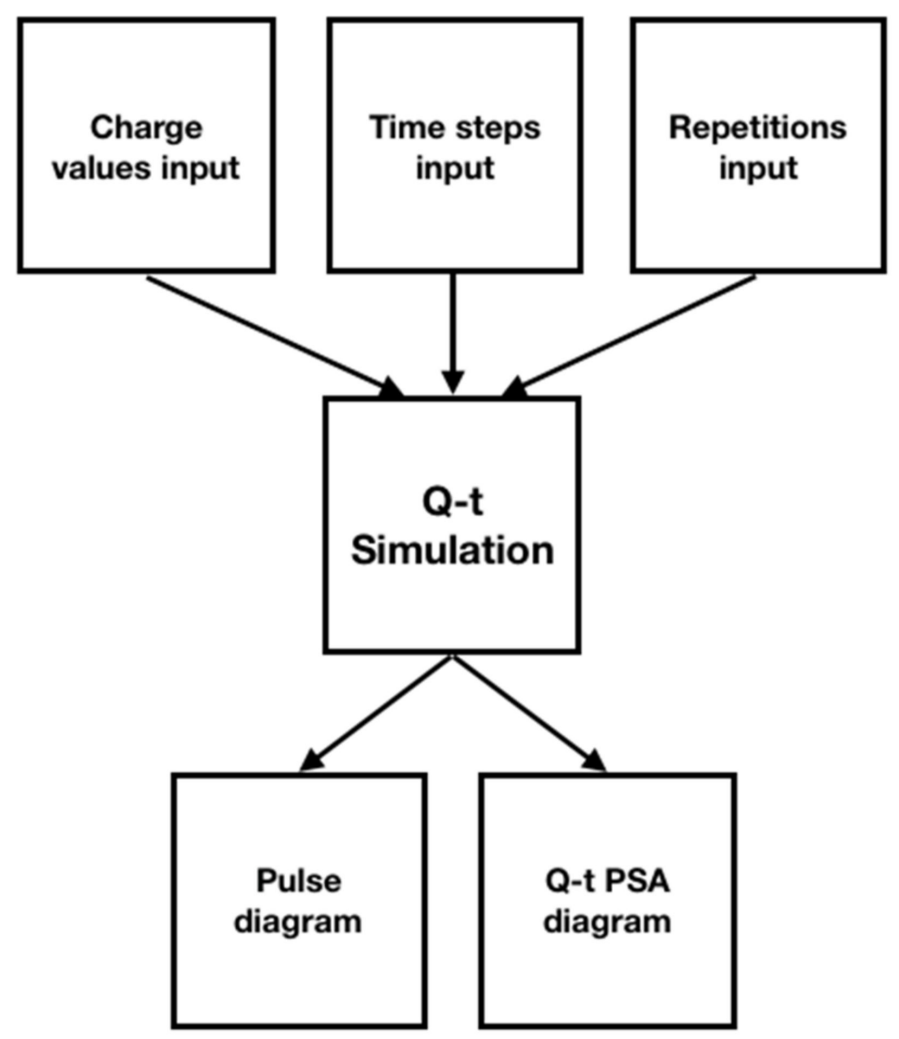

Figure 4. Simulation diagram.

Figure 5 shows the process of creating the PSA clusters. It is obvious from the plots that the transition between different charge levels is significantly more important than the number of repetitions of the pulses and the exact value of its charge. Transitions between high and low pulses create the Q-t PSA clusters in the negative part of the $\Delta Q_{n}$ axis (Figure 5, green, number 1). Transitions between two pulses of resembling values create the Q-t PSA clusters around the $\Delta \mathrm{Q}_{\mathrm{n}}$ axis (Figure 5, red, number $2 \mathrm{a}$ and $2 \mathrm{~b}$ ). Transitions between low and high pulses create the Q-t PSA clusters in the positive part of the $\Delta Q_{n}$ axis (Figure 5, blue, number 3 ). This principle works analogically for the time domain. The different delays between two consecutive pulses of similar values cause different cluster shifts on the $x$-axis $\left(\Delta t_{n}\right)$. Only two ranges of delays were presented in this case-short delays in the range from $\approx 0 \mathrm{~ms}$ to $\approx 4 \mathrm{~ms}$ are represented by clusters $1,2 \mathrm{a}$ and 3 (Figure 5), long delays in the range from $\approx 14 \mathrm{~ms}$ to $\approx 20 \mathrm{~ms}$ are represented by cluster $2 \mathrm{~b}$ (Figure 5 ). 


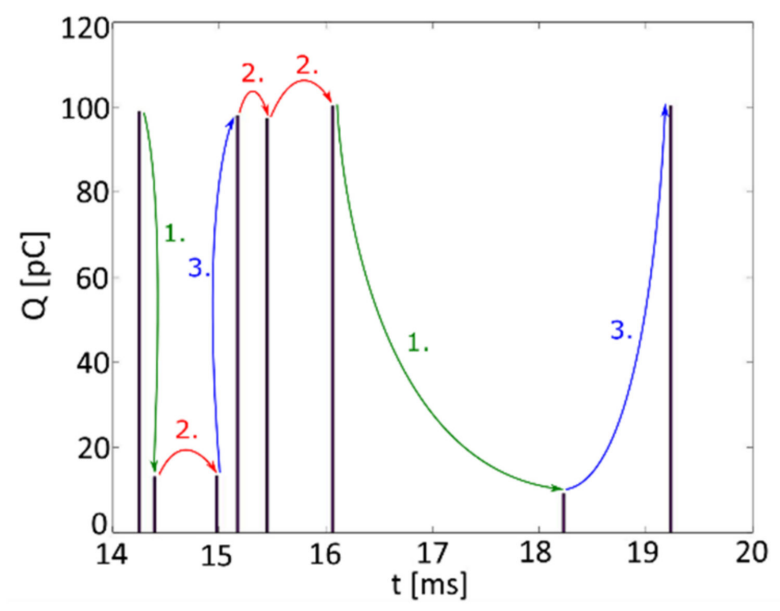

(a)

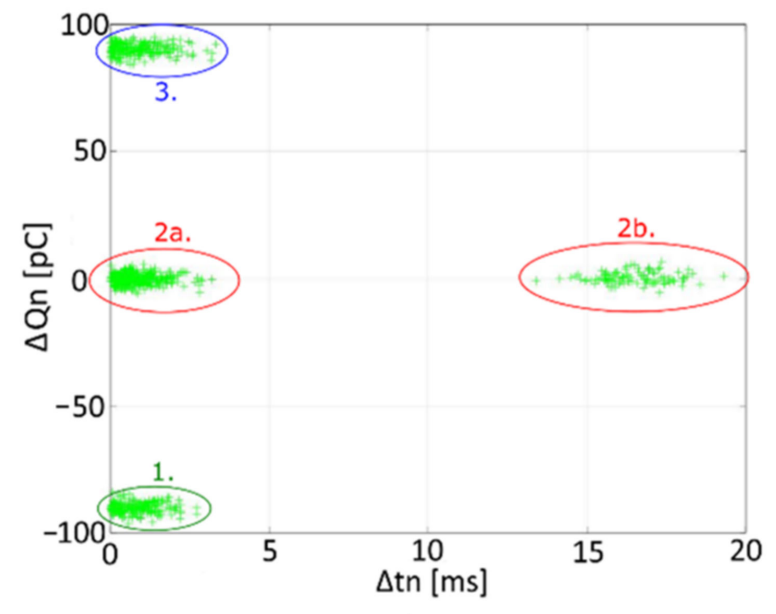

(b)

Figure 5. Impulse transitions in pulse diagram (a) and the Q-t PSA (dependence of charge and time values of consecutive pulses) of simulated corona discharges; (b) sequences of high and low pulses (with time and discharge disturbances).

\subsection{Corona}

Existing experiments showed that pulses of AC corona partial discharges (only Trichels pulses) have an almost constant level of apparent charge [5]. $\Delta Q$ is in a very narrow interval because of the small deviation between charges of consecutive pulses. As shown in Figure 6, the time between two pulses is in the range from tenths of milliseconds up to the whole period.

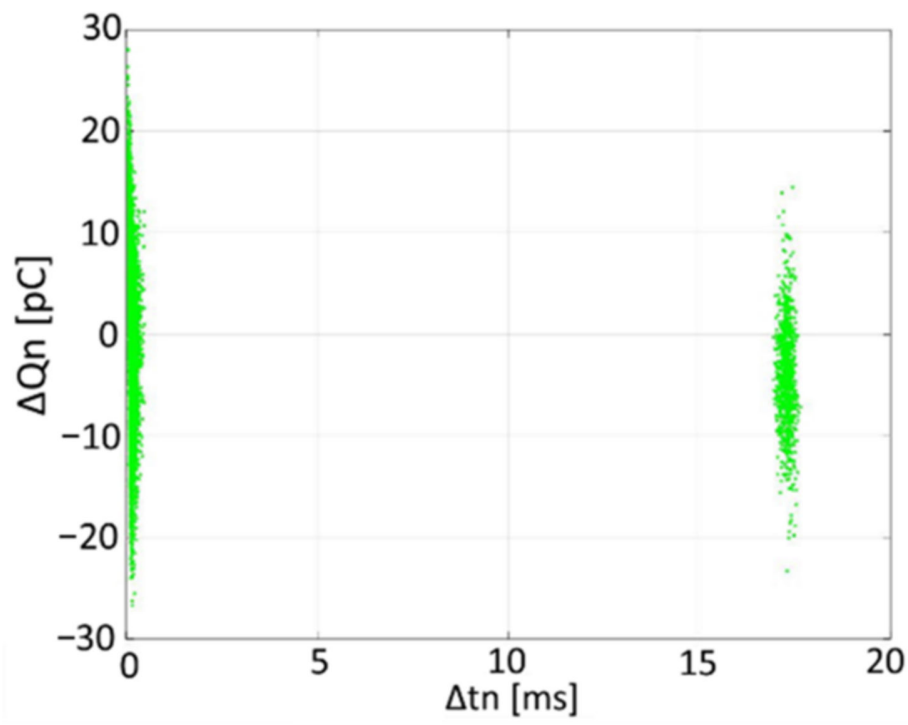

Figure 6. Pulse diagram of measured alternating current (AC) corona (3.4 kV RMS).

The AC corona without streamer impulses (Figures 6 and 7) is the simplest case. There are Trichels pulses around the negative peak of the sine wave with a low scatter of values. 


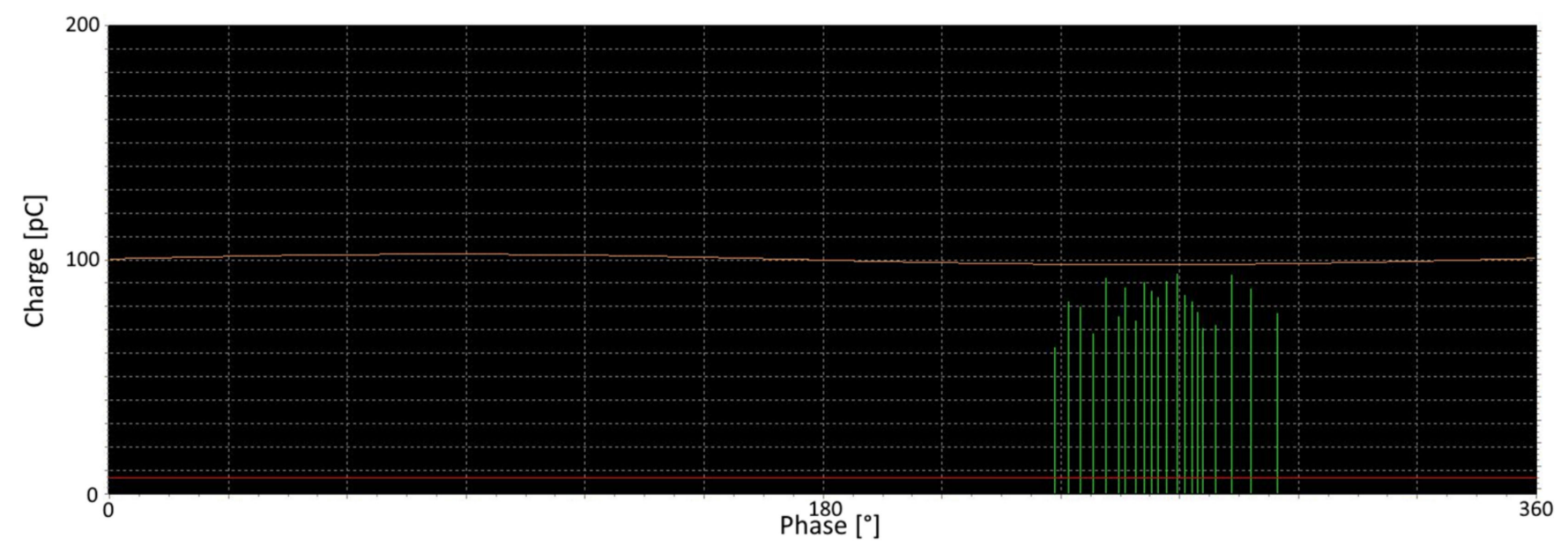

Figure 7. Q-t PSA of measured AC corona (3.4 kV RMS).

The measured data were obtained by measurements on corona needle-plane arrangement in the air under the AC voltage.

The pulse diagram and the Q-t PSA shown in Figures 6 and 7 represent the first stage of the AC corona. The left Q-t PSA cluster around $\Delta t_{n}=0 \mathrm{~ms}$ is created by transients between corona pulses in the negative half of the sine wave (between 13th to 17th ms of a period). The right Q-t PSA cluster is created by transients between the last pulse of the period and the first pulse of the next period (time delay around $14 \mathrm{~ms}$ ).

The simulation of the AC corona (Figure 8) confirms the behaviour of the real measurement Q-t PSA. This simulation has pulses of one charge level and different time delays with added deviation for both parameters. There are only two clusters of similar $\Delta \mathrm{Q}_{\mathrm{n}}$ but with a different time delay (around $\Delta \mathrm{t}_{\mathrm{n}}=0 \mathrm{~ms}$ and around $\Delta \mathrm{t}_{\mathrm{n}}=14 \mathrm{~ms}$ ) as in the case where the real measurement was processed. Values of $\Delta Q_{n}$ are different due to the input values of the simulation. However, it does not affect the Q-t PSA clusters position or the shape.

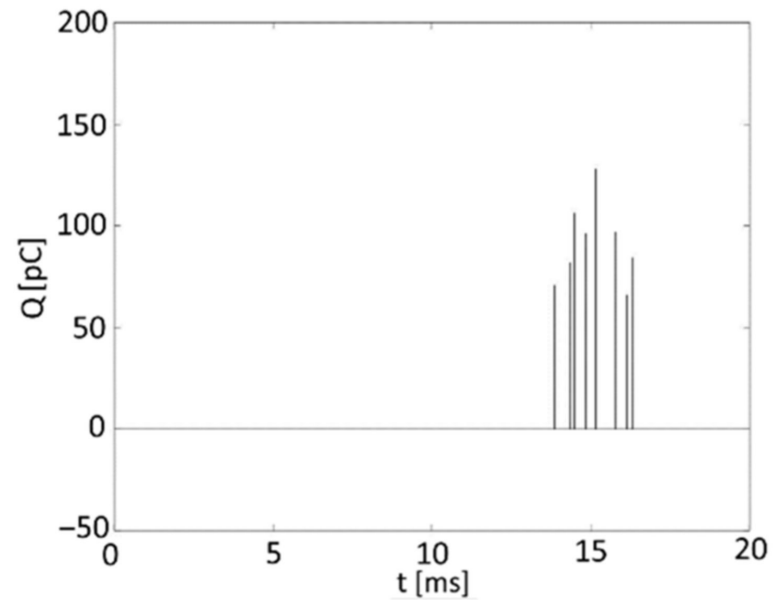

(a)

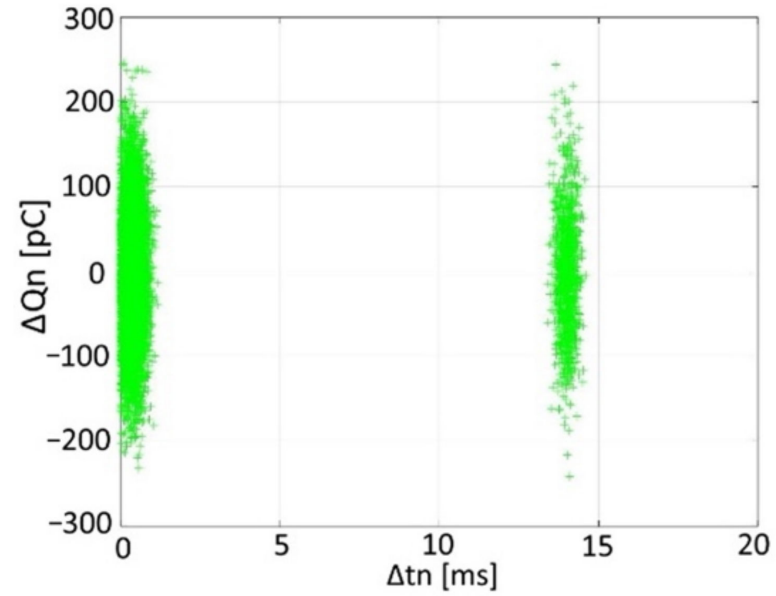

(b)

Figure 8. Pulse diagram of simulated $3.4 \mathrm{kV}$ AC corona (a) and its Q-t PSA (b).

Streamer impulses appear in the positive half of the sine wave when the AC testing voltage for corona arrangement is raised above a certain level. The presence of streamer impulses marks the proximity of the breakdown. The pulse diagram and the Q-t PSA of 
measured AC corona with streamer impulses are shown in Figures 9 and 10; its simulation is shown in Figure 11.

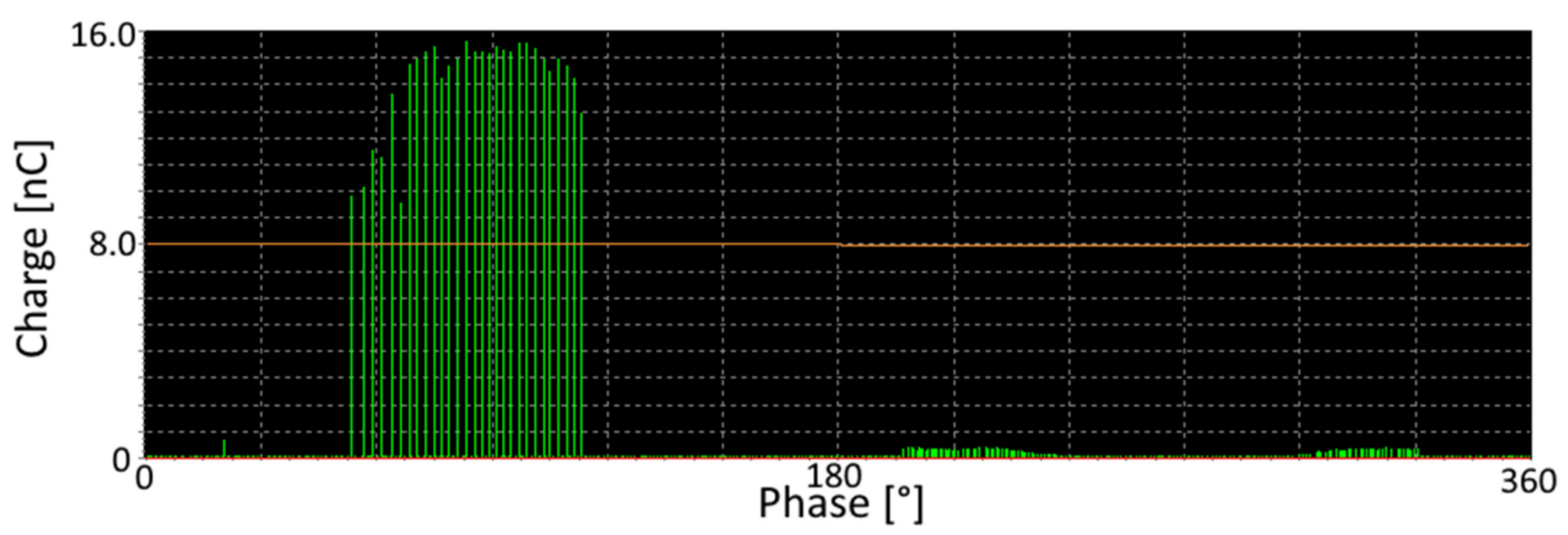

Figure 9. Pulse diagram of measured AC corona with the presence of streamer impulses (6.5 kV RMS).

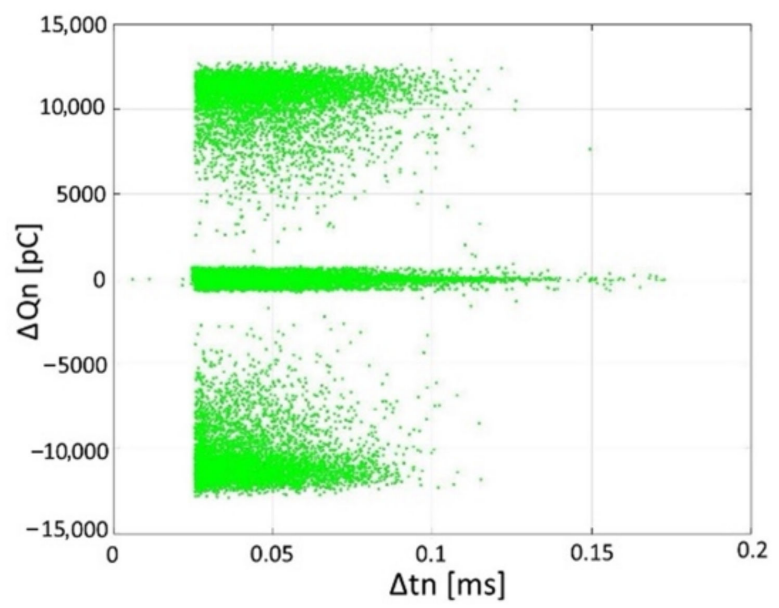

Figure 10. Q-t PSA of measured AC corona with the presence of streamer impulses (6.5 kV RMS).

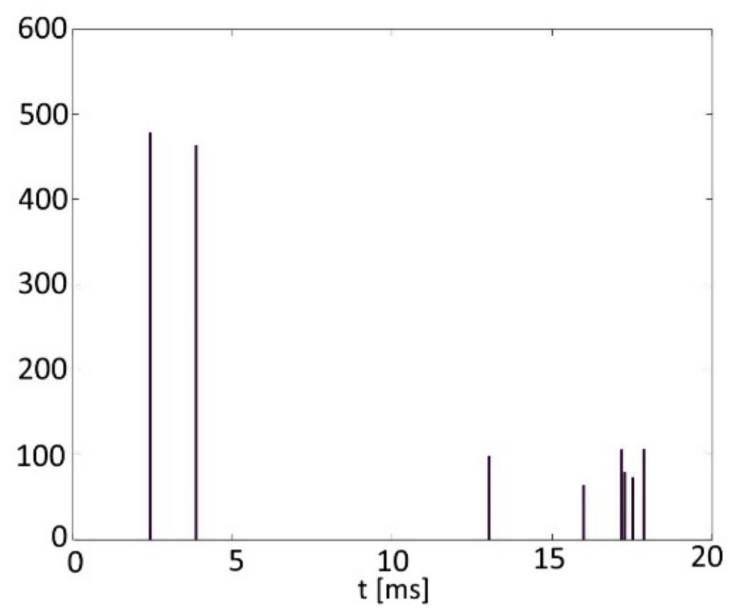

(a)

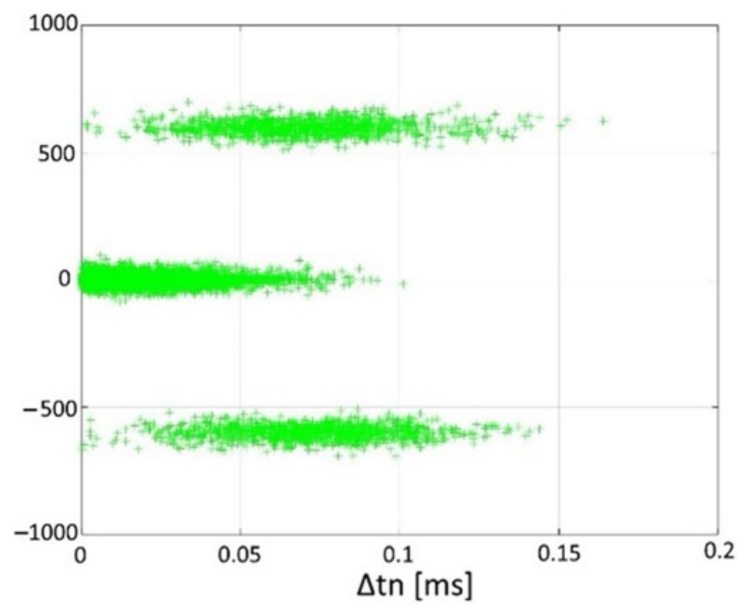

(b)

Figure 11. Pulse diagram of simulated $6.5 \mathrm{kV}$ AC corona with streamer pulses (a) and its Q-t PSA (b). 
The pulse diagram and the Q-t PSA shown in Figures 9 and 10 represent the stage of the AC corona before breakdown. The Q-t PSA created three clusters. The central cluster around $\Delta \mathrm{Q}_{\mathrm{n}}=0 \mathrm{pC}$ is created by differences of transients between Trichels pulses in the negative half of the sine wave (between 10th to 18th ms of a period) and between streamer impulses (between 3rd and 6th ms of a period). The upper Q-t PSA cluster (Figure 10) is created by the transients between the last Trichels pulse and the first streamer pulse in the next period (low pulse to high pulse, see Figure 5). The lower Q-t PSA cluster (Figure 10) is created by the difference between the last streamer impulse and the first Trichels pulse (high pulse to low pulse). All the clusters are in a narrow band of $\Delta t$ due to the high repetition rate of the discharge activity or noise-the upper and the lower clusters are in the range from 0.025 to $0.1 \mathrm{~ms}$, and the central cluster is in the range from 0.025 to $0.15 \mathrm{~ms}$. The gap in $\Delta \mathrm{t}=0-0.025 \mathrm{~ms}$ is caused by a distinguishing ability of the measurement system. This presumption is based on the knowledge gathered from the simulation of Q-t PSA creation shown in Figure 5.

The simulation of the AC corona with streamer impulses (Figure 11) shows the behaviour of ideal measurement with a low repetition rate of partial discharges and ideal noise filtration. This simulation has pulses of two charge levels and different time delays with added deviation for both parameters. Simulated Q-t PSA has a similar shape and structure as the real measurement. The differences in $\Delta \mathrm{Qn}$ and in the time delay are possibly caused by a lower repetition rate with no added noise. Values of $\Delta$ Qn are different because of the input values of the simulation; nonetheless, it does not affect the Q-t PSA clusters' position or the shape.

\subsection{Surface Discharges}

AC surface discharges start with a small amplitude and low repetition rate. The repetition rate of the pulses grows with the rise of the voltage. After the growth occurs, pulses with a higher amplitude start to appear with rising voltage until the discharges are big enough to bridge over insulation and cause a breakdown.

Surface discharges under AC conditions embody the pulse diagram shape shown in Figure 12. Triangle-shaped patterns with peaks in voltage maximum appear in both periods of the sine wave with a higher repetition rate of the pulses with a smaller amplitude and vice versa.

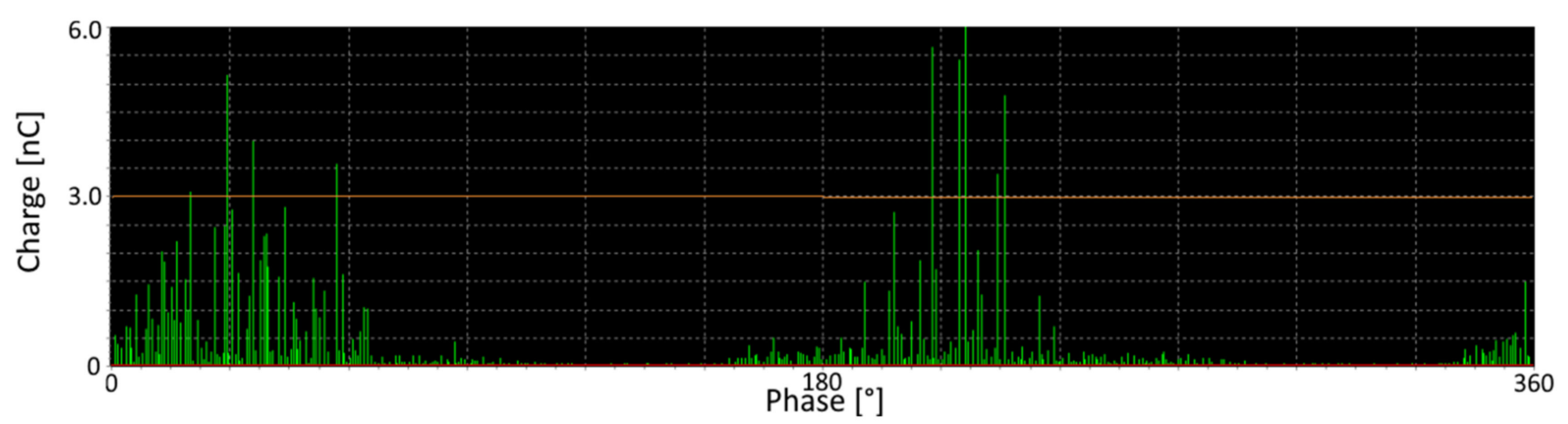

Figure 12. Pulse diagram of measured AC surface discharges $(4 \mathrm{kV})$.

The measured data were obtained by measurements at surface discharges arrangement with a Relanex insulating sheet under the AC voltage.

The pulse diagram in Figure 12 and the Q-t PSA in Figure 13 represent the AC surface discharges. The only Q-t PSA cluster is created around $\Delta \mathrm{Q}_{\mathrm{n}}=0 \mathrm{pC}$ (from $\Delta \mathrm{t}_{\mathrm{n}}=0.025 \mathrm{~ms}$ to $\Delta \mathrm{t}_{\mathrm{n}}=0.14 \mathrm{~ms}$ ) by the pulse transients with small amplitude deviances. Scattered points above the cluster are created by the charge differences between high pulses with lower repetition rate and more frequent low charge pulses. Scattered pulses below the cluster are created vice versa by the charge differences between low and high pulses. 


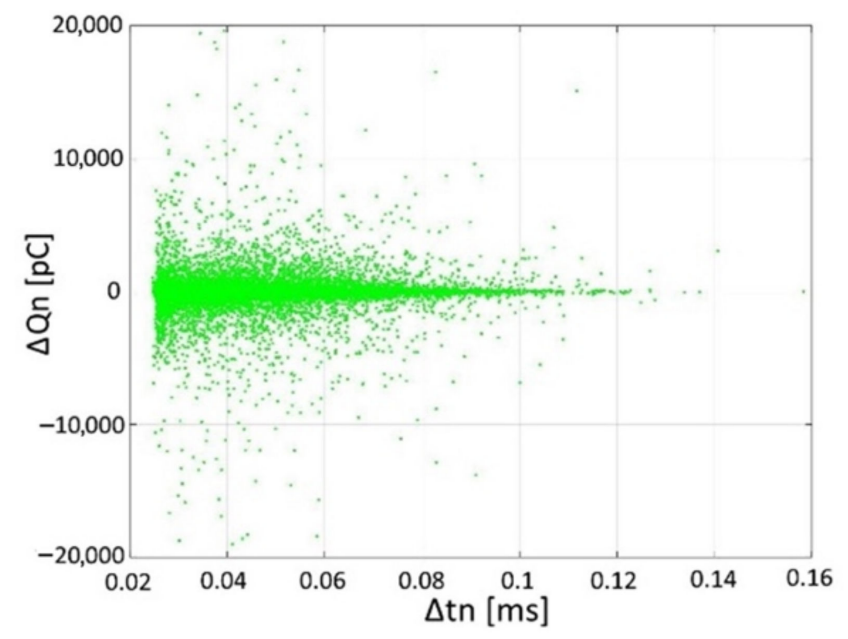

Figure 13. Q-t PSA of measured AC surface discharges $(4 \mathrm{kV})$.

The simulation of the AC surface discharges (Figure 14) confirms the behaviour of the real measurement Q-t PSA. This simulation has pulses of three charge levels and different time delays with added deviance for both parameters. There is only one cluster around $\Delta \mathrm{Q}_{\mathrm{n}}=0 \mathrm{pC}$ (from $\Delta \mathrm{t}_{\mathrm{n}}=0 \mathrm{~ms}$ to $\Delta \mathrm{t}_{\mathrm{n}}=14 \mathrm{~ms}$ ) in shape as in the case where the real measurement was processed. Values of $\Delta \mathrm{Q}_{\mathrm{n}}$ are different from the input values of the simulation; however, it does not affect the Q-t PSA cluster position or the shape.

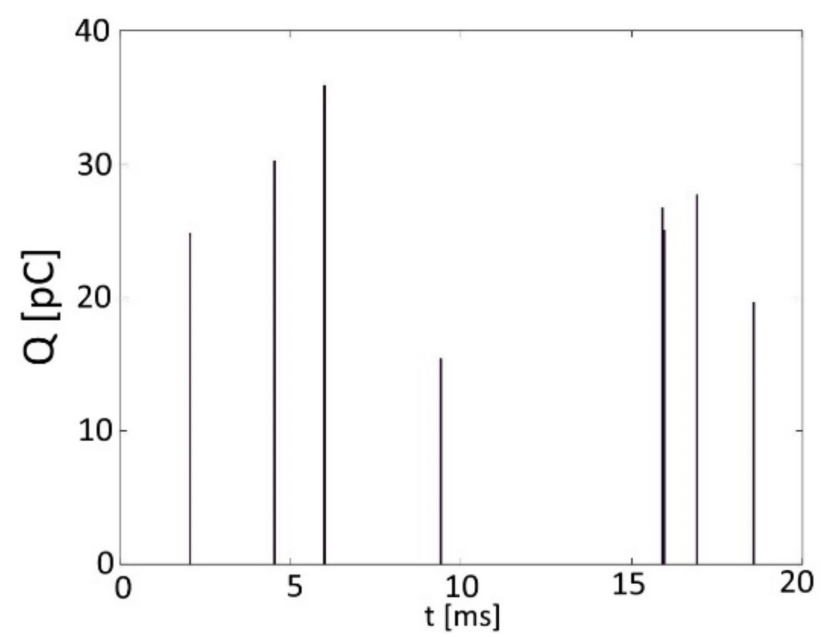

(a)

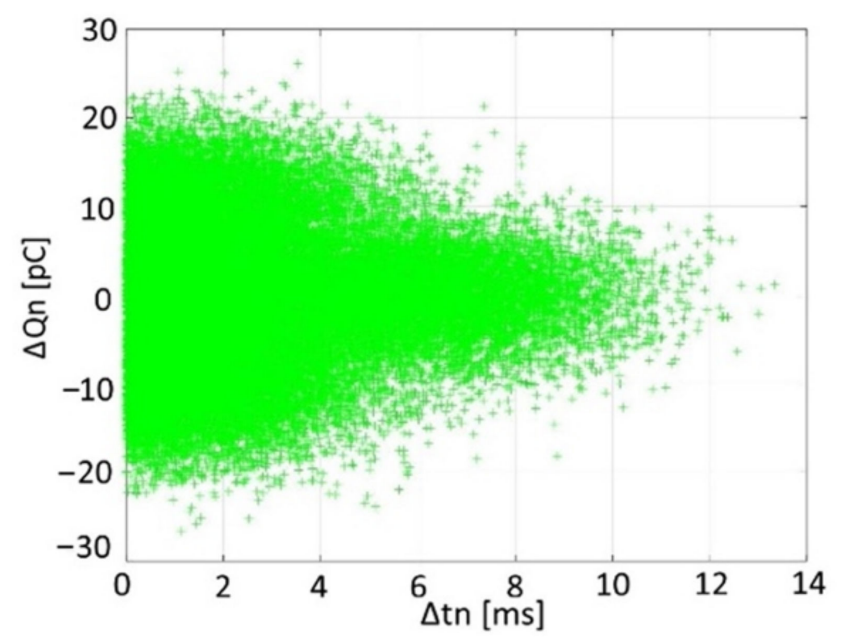

(b)

Figure 14. Pulse diagram of simulated $4 \mathrm{kV}$ AC surface discharges (a) and its Q-t PSA (b).

\subsection{Internal Discharges}

AC Internal discharges are distinguished by the characteristic "rabbit ears" clearly visible at PRPD. Mentioned structures are present in both halves of the sine wave, and they are surrounded by pulses with much lower amplitude. Peaks become taller with the rising voltage until complete breakdown.

The measured data were obtained by measurements at internal discharges arrangement with PMMA insulating sheet with the air cavity immersed in the oil tank under the AC voltage.

The pulse diagram and the Q-t PSA shown in Figures 15 and 16 represent AC internal PD activity. The cluster displayed on Q-t PSA from $\Delta \mathrm{tn}=0-3 \mathrm{~ms}$ and $\Delta \mathrm{Qn}=-1000-1000 \mathrm{pC}$ 
and the cluster on the Q-t PSA coordinates from $\Delta \mathrm{tn}=4-12 \mathrm{~ms}$, and $\Delta \mathrm{Qn}=-3500-3500 \mathrm{pC}$ have a similar shape (left-side oriented triangle with a line on $\Delta \mathrm{Qn}=0 \mathrm{pC}$ ) but in a different scale. There are two more horizontal lines around $\Delta \mathrm{Qn}= \pm 1500 \mathrm{pC} ; \Delta \mathrm{tn}=0-3 \mathrm{~ms}$.

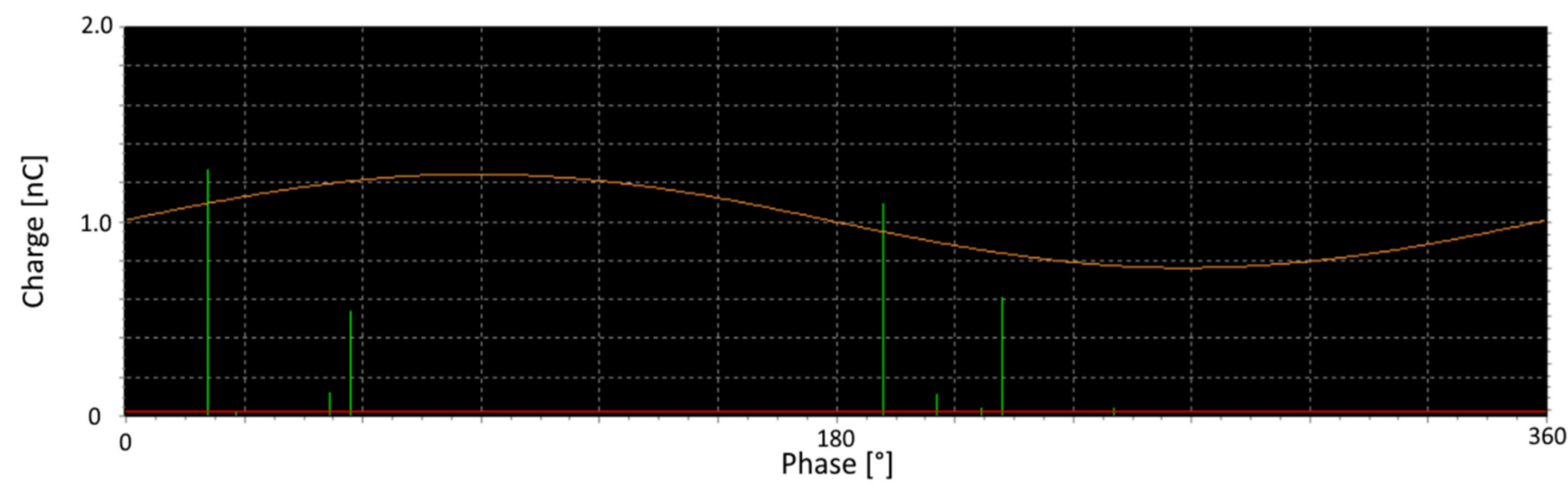

Figure 15. Pulse diagram of measured AC internal PD (40 kV).

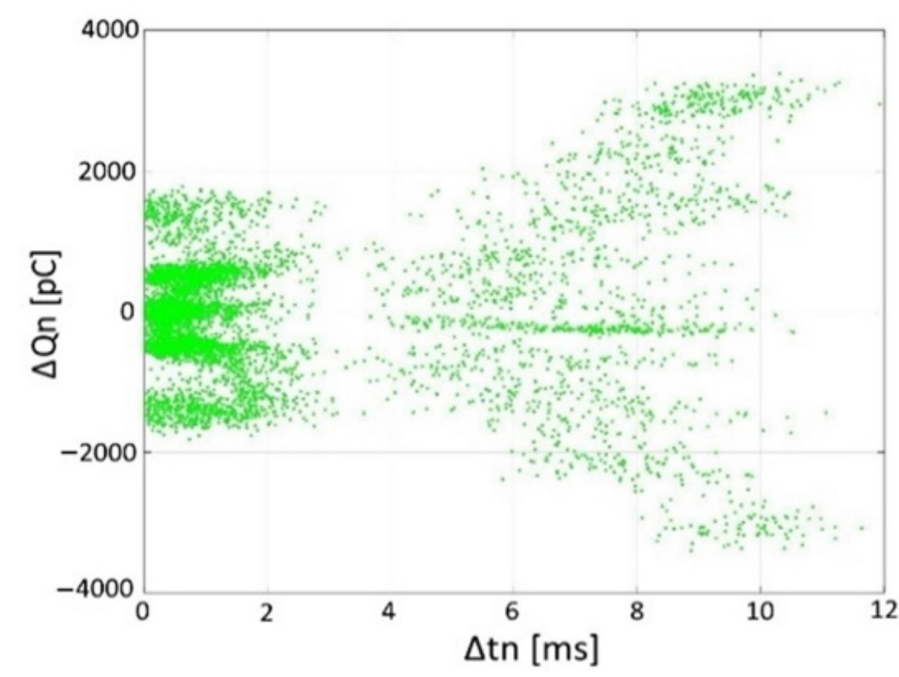

Figure 16. Q-t PSA of measured AC internal PD (40 kV).

Simulation of the AC internal PDs (Figure 17) was undertaken only partially due to its complexity (the outcome of Q-t PSA of measured AC internal PD $(40 \mathrm{kV})$ contains two central clusters and three pairs of symmetric clusters). Two main clusters were simulated roughly-two left-side oriented triangles with a central line around $\Delta \mathrm{Q}_{\mathrm{n}}=0 \mathrm{pC}$. The bigger clusters are created by multiple smaller clusters continuously verging into the other, as in the case where the data were measured. Two clusters are missing at $\Delta \mathrm{Q}_{\mathrm{n}}= \pm 700 \mathrm{pC}$; $\Delta t_{n}=0-0.6 \mathrm{~ms}$ in this simulation due to the presence of the inputs of only eight variables. 


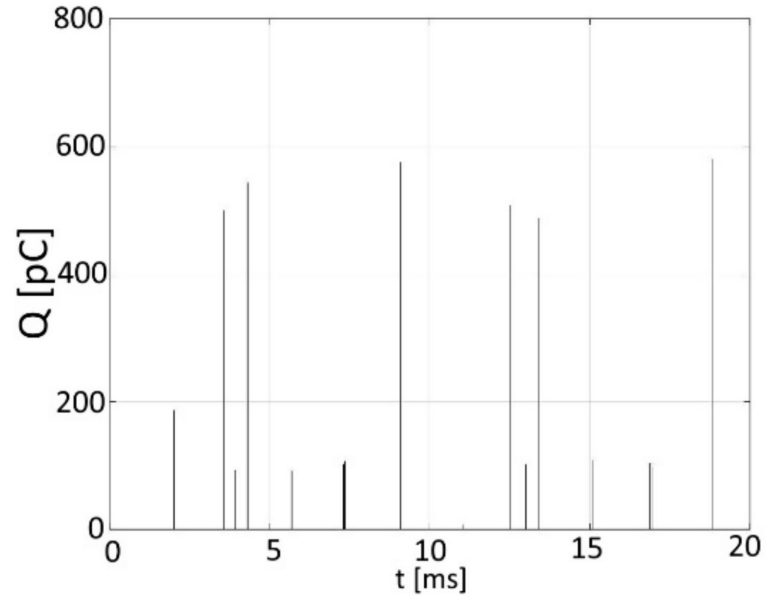

(a)

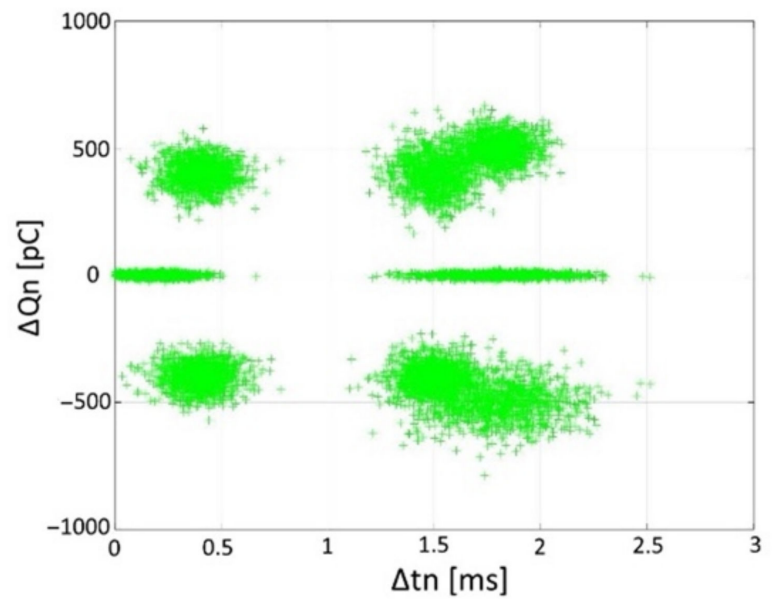

(b)

Figure 17. Pulse diagram of simulated $40 \mathrm{kV}$ AC internal PD (a) and its Q-t PSA (b).

3.4. Simulation of Direct Current Negative (DCN) Corona Pulse Sequence Analysis (PSA) Clusters

Figure 18 shows pulse diagrams of measured DCN corona at $3.5 \mathrm{kV} ; 5 \mathrm{kV} ; 5.5 \mathrm{kV}$; and $6 \mathrm{kV}$ voltage levels. Charge values for $3.5 \mathrm{kV}$ were in the range of 10 to $17 \mathrm{pC}$. Pulse repetition rate extensively increased, and a majority of the pulses moved to the range of 30 to $40 \mathrm{pC}$ at the $5 \mathrm{kV}$ voltage level. The next voltage increments just raised charge values closer to $40 \mathrm{pC}$. From the pulse diagrams in Figure 18 it is not possible to distinguish the PD type. That is a reason why it is necessary to process data through a PSA algorithm. PSA plots for DCN corona (Figure 19) correlate with a later stage of AC corona (Section 3.1).
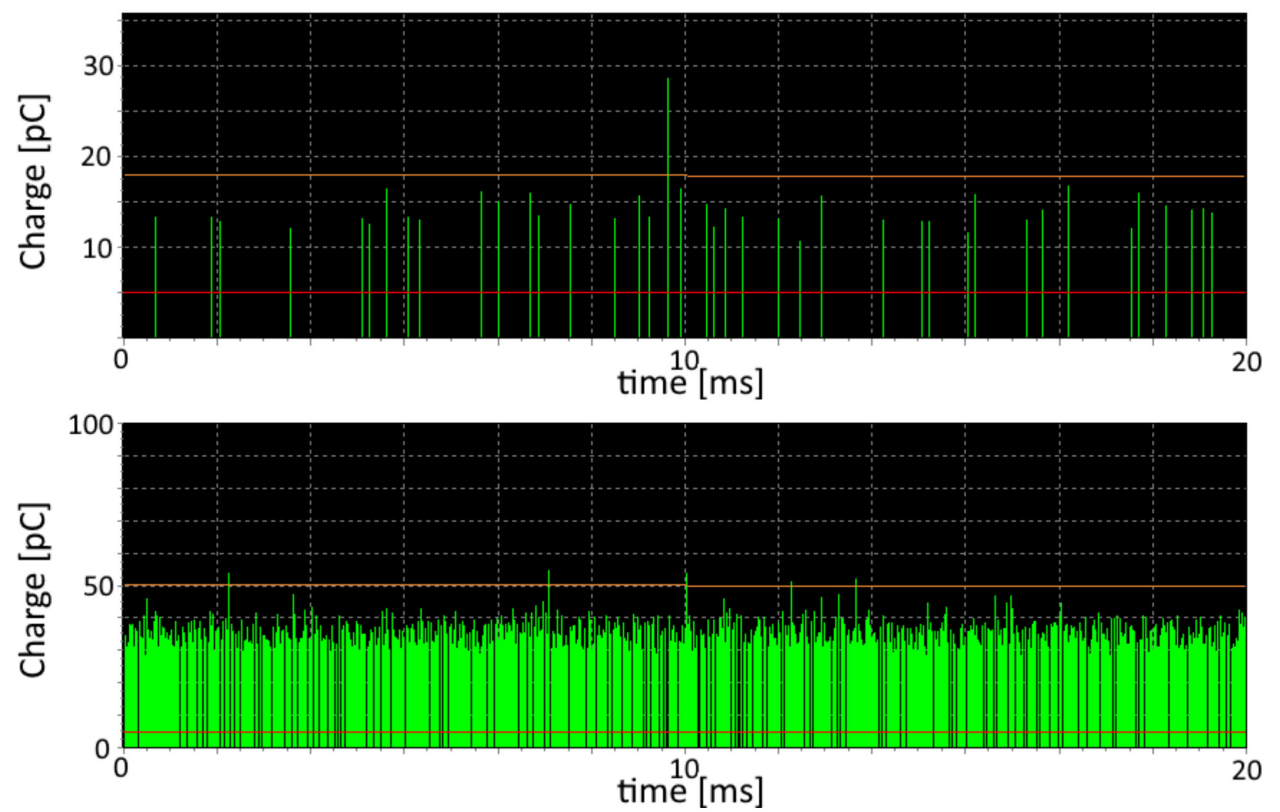

Figure 18. Cont. 

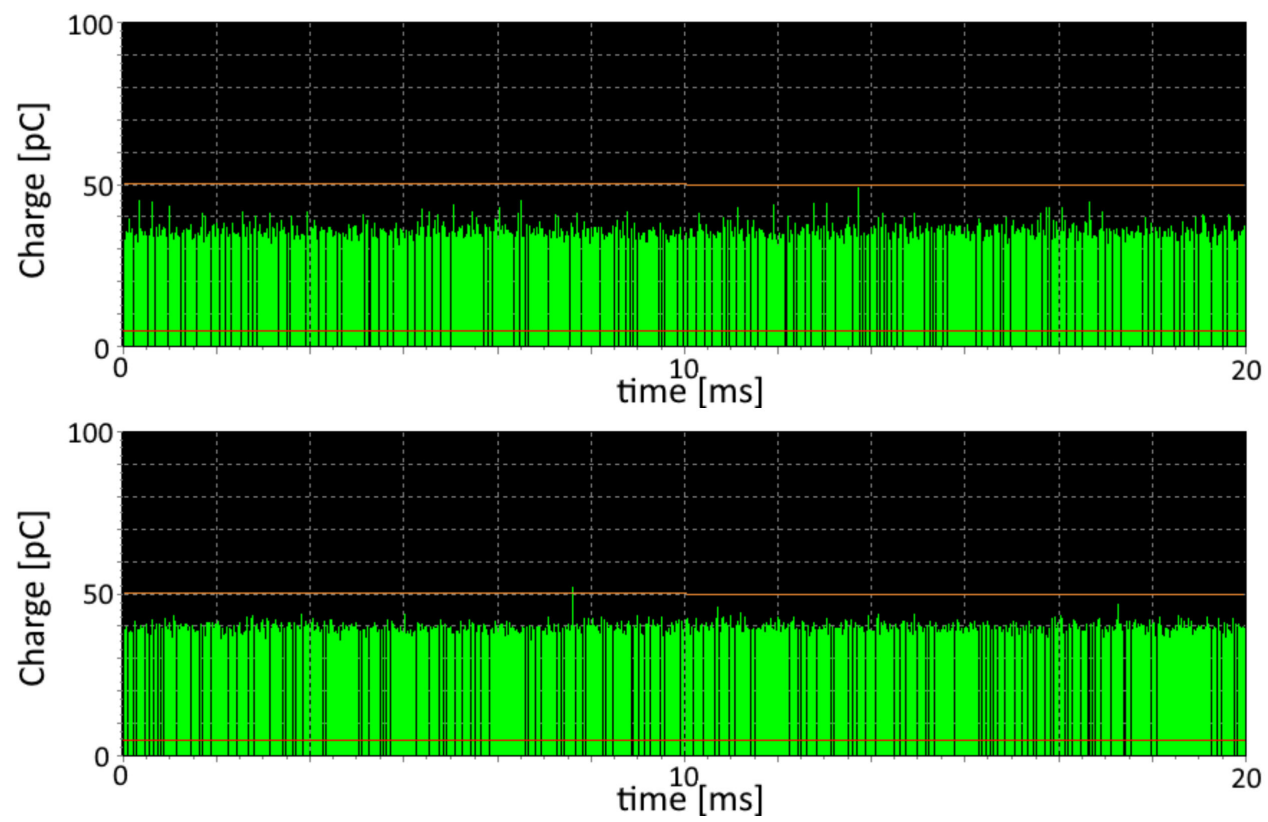

Figure 18. Pulse diagram of measured DCN corona (from top $U=3.5 \mathrm{kV}$; $U=5 \mathrm{kV}$; $U=5.5 \mathrm{kV}$; $\mathrm{U}=6 \mathrm{kV})$.

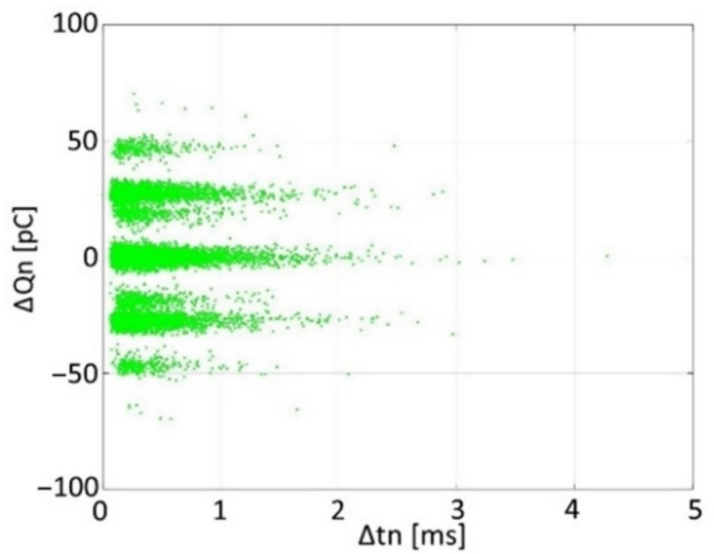

(a)

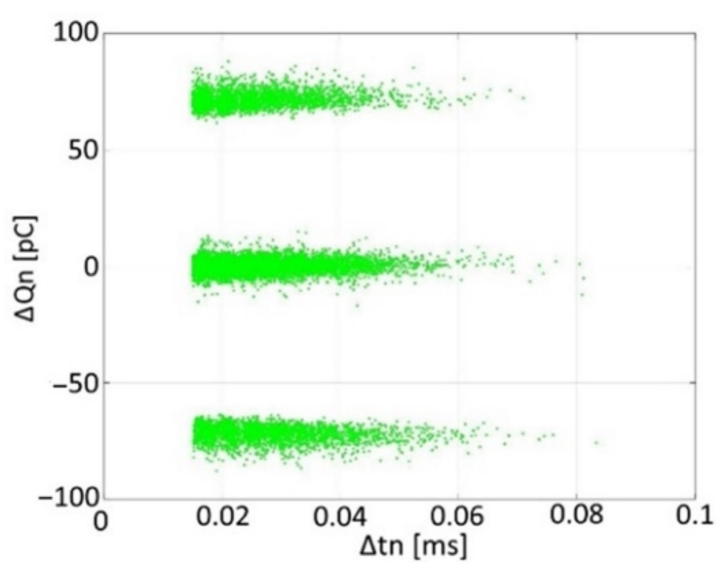

(c)

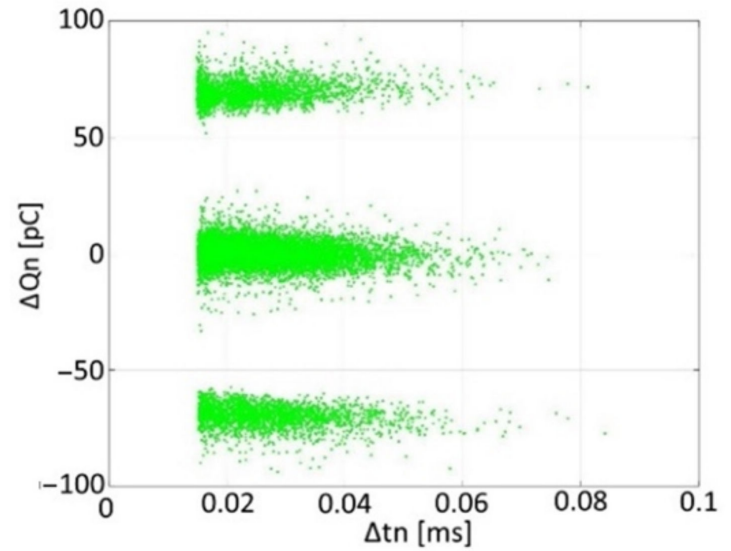

(b)

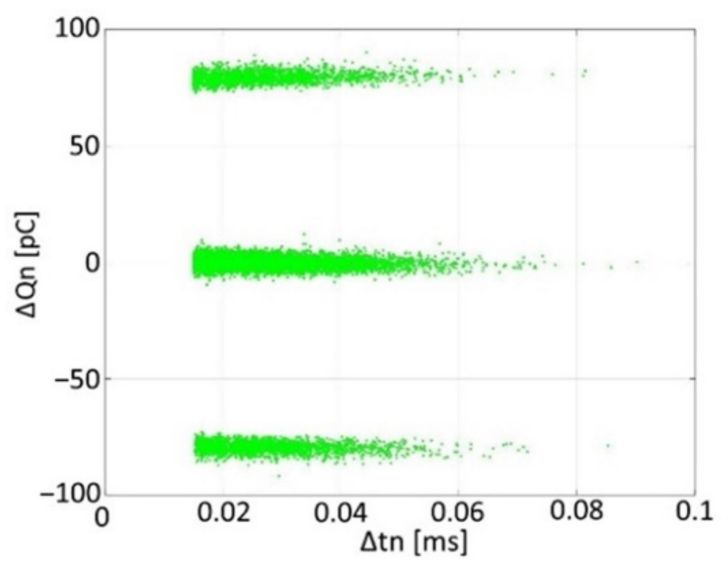

(d)

Figure 19. Q-t PSA of measured DCN corona $((\mathbf{a}) \mathrm{U}=3.5 \mathrm{kV}$; (b) $\mathrm{U}=5 \mathrm{kV}$; (c) $\mathrm{U}=5.5 \mathrm{kV}$; (d) $\mathrm{U}=6 \mathrm{kV})$. 
DCN corona PSA plots measured at voltages of $3.5 \mathrm{kV} ; 5 \mathrm{kV} ; 5.5 \mathrm{kV}$; and $6 \mathrm{kV}$ are shown in Figure 19. The plot for $3.5 \mathrm{kV}$ consists of three pairs of symmetrical lines around the central cluster-the first pair is in $\pm 15 \mathrm{pC}$, the second is in $\pm 25 \mathrm{pC}$, and the third is in $\pm 50 \mathrm{pC}$. Pulses with the highest repetition rate (Figure 18 shows pulses of approximately $15 \mathrm{pC}$.) create a cluster around $0 \mathrm{pC}$, and transition to other values creates other lines. There are no pulses of a lower charge for voltages $5 ; 5.5$, and $6 \mathrm{kV}$; hence the PSA plots have only the central cluster and one pair symmetrical clusters in charge values of approximately $\pm 75 \mathrm{pC}$. This follows the presence of pulses with charge value around $115 \mathrm{pC}$ (transient between pulses $40 \mathrm{pc}$ and $115 \mathrm{pC}$ results in point of $\Delta \mathrm{Q}=75 \mathrm{pC}$, resp. $\Delta \mathrm{Q}=-75 \mathrm{pC}$ for transient of $115 \mathrm{pC}$ and $40 \mathrm{pC}$ ) in measurements. Those pulses have a very low repetition rate and they are not displayed in pulse diagrams. Increasing voltage lowers the deviation of charge values which causes narrowing of the sidelines in the PSA plot until the appearance in Figure 19 for $6 \mathrm{kV}$.

\section{Conclusions}

The absence of the phase is the major issue for distinguishing a DC PD source. By substitution of the phase domain with the time domain, PRPD is no longer applicable, and pulse diagrams do not provide enough information about a PD source in DC. The simulations were made to understand the basic principles of the Q-t PSA formation and to help adjust and improve future PD data procession and evaluation. In this case, AC partial discharges were used as the first step of Q-t PSA verification for DC conditions. This approach was chosen because the AC PD has deeper behaviour knowledge and easier data acquisition than a DC PD. The major contribution of this work is the illustration of the Q-t PSA as a suitable method for the determination of a PD source. The simulations were compared and validated with PSA outcomes from data measured on different PD arrangements with a good match of the data and PD source type recognition. Results acquired from noisy measurement are almost the same as the results acquired from noiseless simulations. This fact supports the assumption that the Q-t PSA is more noise resistant than the Q-Q PSA. Q-t PSA functionality under DC voltage stress has to be confirmed in a further investigation.

Author Contributions: Investigation, O.K.; measurement, O.K.; simulations, O.K.; plan of the experiment, J.P.; specific data measurement, J.P.; supervision, J.P.; writing—original draft, O.K. and J.P.; writing - review and editing, O.K. and J.P. All authors have read and agreed to the published version of the manuscript.

Funding: This research has been supported by the Ministry of Education, Youth and Sports of the Czech Republic under the project OP VVV Electrical Engineering Technologies with High-Level of Embedded Intelligence CZ.02.1.01/0.0/0.0/18_069/0009855 and by the Student Grant Agency of the University of West Bohemia in Pilsen, grant No. SGS-2021-003 "Materials, technologies and diagnostics in electrical engineering".

Institutional Review Board Statement: Not applicable.

Informed Consent Statement: Not applicable.

Conflicts of Interest: The authors declare no conflict of interest.

\section{References}

1. Fromm, U. Interpretation of partial discharges at dc voltages. IEEE Trans. Dielectr. Electr. Insul. 1995, 2, 761-770. [CrossRef]

2. Madhar, S.A.; Mraz, P.; Mor, A.R.; Ross, R. Empirical analysis of partial discharge data and innovative visualization tools for defect identification under DC stress. Int. J. Electr. Power Energy Syst. 2020, 123, 106270. [CrossRef]

3. Pompili, M.; Mazzetti, C.; Bartnikas, R. Partial discharge pulse sequence patterns and cavity development times in transformer oils under ac conditions. IEEE Trans. Dielectr. Electr. Insul. 2005, 12, 395-403. [CrossRef]

4. Ryan, H.M. High-Voltage Engineering and Testing; Institution of Engineering and Technology: London, UK, 2013.

5. Mraz, P.; Treyer, P.; Hammer, U. Evaluation and Limitations of Corona Discharge Measurements-An Application Point of View. In Proceedings of the 2016 International Conference on Condition Monitoring and Diagnosis (CMD), Xi'an, China, 25-28 September 2016; pp. 273-276. 
6. Hoof, M.; Patsch, R. Analyzing partial discharge pulse sequences-A new approach to investigate degradation phenomena. In Proceedings of the 1994 IEEE International Symposium on Electrical Insulation, Pittsburgh, PA, USA, 5-9 June 1994; pp. 327-331.

7. Pihera, J.; Haller, R.; Kozak, O.; Hornak, J. Corona pulse sequence analysis at DC voltage. In Proceedings of the 17th International Scientific Conference on Electric Power Engineering (EPE), Prague, Czech Republic, 16-18 May 2016; pp. 1-6.

8. Kindl, V.; Skala, B.; Pechanek, R.; Kus, V.; Hornak, J. Low-pass filter for HV partial discharge testing. Sensors 2018, 18, 482. [CrossRef] [PubMed]

9. Pirker, A.; Schichler, U. Partial discharges at DC voltage-Measurement and pattern recognition. In Proceedings of the 2016 International Conference on Condition Monitoring and Diagnosis (CMD), Xi'an, China, 25-28 September 2016; pp. 287-290.

10. Pihera, J.; Trnka, P.; Kozák, O.; Hornak, J. Pulse sequence analysis of corona discharge at DC voltage. In Proceedings of the 2016 Diagnostic of Electrical Machines and Insulating Systems in Electrical Engineering (DEMISEE), Papradno, Slovakia, 20-22 June 2016; pp. 71-76.

11. Kreuger, F.H. Partial Discharge Detection in High-Voltage Equipment; Butterworths: London, UK, 1989.

12. Madhar, S.A.; Mráz, P.; Mor, A.R.; Ross, R. Study of corona configurations under DC conditions and recommendations for an identification test plan. Int. J. Electr. Power Energy Syst. 2020, 118, 105820. [CrossRef]

13. Mantach, S.; Ashraf, A.; Janani, H.; Kordi, B. A convolutional neural network-based model for multi-source and single-source partial discharge pattern classification using only single-source training set. Energies 2021, 14, 1355. [CrossRef]

14. Götz, T.; Kirchner, H.; Backhaus, K. Partial discharge behaviour of a protrusion in gas-insulated systems under dc voltage stress Energies 2020, 13, 3102. [CrossRef]

15. Cavalini, X.; Montanari, A.; Tozzi, C.G.; Chen, M. Diagnostic of HVDC systems using partial discharges. IEEE Trans. Dielectr. Electr. Insul. 2011, 18, 275-284. [CrossRef]

16. Pihera, J.; Haller, R.; Mraz, P. Partial discharges evaluation at DC voltage. In Proceedings of the 2014 15th International Scientific Conference on Electric Power Engineering (EPE), Brno, Czech Republic, 12-14 May 2014; pp. 441-445.

17. Michau, G.; Hsu, C.-C.; Fink, O. Interpretable detection of partial discharge in power lines with deep learning. Sensors 2021, 21, 2154. [CrossRef] [PubMed]

18. IEC. IEC 60270. In High-Voltage Test Techniques_Partial Discharge Measurements; IEC: Geneva, Switzerland, 2015.

19. Hoof, M.; Patsch, R. Pulse-sequence analysis: A new method for investigating the physics of PD-induced ageing. Sci. Meas. Technol. IEE Proc. 1995, 142, 95-101. [CrossRef]

20. Patsch, R.; Hoof, M. Pulse-sequence analysis, a way to get a better insight into the physics of discharges. In Proceedings of the International Conference on Partial Discharge, London, UK, 28-30 September 1993.

21. Gockenbach, E. High Voltage Engineering Testing. In Chapter 17: Partial Discharges Measuring Techniques; Ryan, H.M., Ed.; Institution of Engineering and Technology: London, UK, 2013. 